\title{
THRESHOLD DETERMINATION FOR LOCAL INSTANTANEOUS SEA SURFACE HEIGHT DERIVATION WITH ICEBRIDGE DATA IN BEAUFORT SEA
}

\author{
Chaohui Zhu ${ }^{1}$, Shengkai Zhang ${ }^{1, *}$, Feng Xiao ${ }^{1, \dagger}$, Jiaxing Li $^{1}$, Lexian Yuan ${ }^{1}$, Yu Zhang ${ }^{1}$, Tingting Zhu ${ }^{2}$ \\ ${ }^{1}$ Chinese Antarctic Center of Surveying and Mapping, Wuhan University, Wuhan, 430079, China \\ -chzhu@whu.edu.cn, zskai@whu.edu.cn,shaw89@whu.edu.cn \\ ${ }^{2}$ State Key Laboratory of Information Engineering in Surveying, Mapping and Remote Sensing (LIESMARS), \\ Wuhan University, Wuhan, 430079, China-530409689@qq.com
}

Commission III, WG III/9

KEY WORDS: IceBridge, optimal threshold, Sea surface reference, Beaufort sea

\begin{abstract}
:
The NASA Operation IceBridge (OIB) mission is the largest program in the Earth's polar remote sensing science observation project currently, initiated in 2009, which collects airborne remote sensing measurements to bridge the gap between NASA's ICESat and the upcoming ICESat-2 mission. This paper develop an improved method that optimizing the selection method of Digital Mapping System (DMS) image and using the optimal threshold obtained by experiments in Beaufort Sea to calculate the local instantaneous sea surface height in this area. The optimal threshold determined by comparing manual selection with the lowest (Airborne Topographic Mapper) ATM L1B elevation threshold of $2 \%, 1 \%, 0.5 \%, 0.2 \%, 0.1 \%$ and $0.05 \%$ in A, B, C sections, the mean of mean difference are $0.166 \mathrm{~m}$, $0.124 m, 0.083 m, 0.018 m, 0.002 m$ and $-0.034 m$. Our study shows the lowest L1B data of $0.1 \%$ is the optimal threshold. The optimal threshold and manual selections are also used to calculate the instantaneous sea surface height over images with leads, we find that improved methods has closer agreement with those from L1B manual selections. For these images without leads, the local instantaneous sea surface height estimated by using the linear equations between distance and sea surface height calculated over images with leads.
\end{abstract}

\section{INTRODUCTION}

The sea ice of Beaufort Sea is experiencing the fastest rate of sea ice decline and greatest interannual variance anywhere in the Arctic (Zhang et al., 2018). The primary goal of the ongoing NASA Operation IceBridge mission is to utilize a suite of instruments including radar and laser altimeters to engage in large-scale surveys of Arctic and Antarctic sea ice on an annual basis (Kurtz et al., 2013) and make airborne altimetry measurements over the ice sheets and sea ice to extend and improve the record of observations begun by ICESat and production of a long-term, ice altimetry record. Using visible imagery and altimetry data to identify leads and retrieve sea ice freeboard has been accomplished in both satellite and airborne data sets (Kurtz et al., 2008, Connor et al., 2009, Kwok et al., 2004). DMS L1B images which were taken simultaneously with the ATM L1B data are used to manually identify leads, because of the surface height of leads is theoretically lower than that of the nearby snow or sea ice surface (Zwally et al., 2008, Yi et al., 2011, Price et al., 2015), and the average height of the footprints by manual selection fall into leads is taken as ground truth to validate five difference threshold of the lowest L1B data in four L1B files sections of Bellingshausen Sea. The threshold of $0.2 \%$ has a similar sea surface height with manual selection and is used to calculate instantaneous sea surface height (Wang et al., 2013). An automated lead detection algorithm of Sea Ice Lead Detection Algorithm using Minimal Signal (SILDAMS) has been developed to identify leads and sea ice (Onana et al., 2012). Manual lead identification and SILDAMS algorithm are used to identify leads, the average height of the footprints within leads is taken as the sea surface

\footnotetext{
* Corresponding author

$\dagger$ Corresponding author
}

height (SSH) reference (Kurtz et al., 2013). An automated approach was developed to determine SSHs by combining DMS images, ATM L1B's apparent reflectivity and statistical discrimination (Wang et al., 2016). The purpose of this paper is to use ATM L1B elevation data and DMS images to obtain the optimal threshold for local instantaneous sea surface height calculations in the Arctic Beaufort Sea, and use this threshold to calculate the instantaneous sea surface height, which can be used as a sea surface high reference for sea ice freeboard calculations.

\section{DATA DESCRIBE}

In this section, we describe ATM and DMS data sets used in our study, which can be available at National Snow and Ice Data Center (NSIDC).

\subsection{Airborne Topographic Mapper}

The ATM is a scanning LIDAR developed by NASA, foremost of which is the measurement of changing polar sea ice, icecaps and glaciers. The ATM combined with a differential GPS system for aircraft positioning and an inertial navigation system (INS) to measure aircraft orientation, which operated at a wavelength of $532 \mathrm{~nm}$ with a pulse repetition frequency of $5 \mathrm{kHz}$ and a scan rate of $20 \mathrm{~Hz}$; the off-nadir scan angle is $15^{\circ}$ (T2 scanner), $23^{\circ}$ (T3 scanner) or $30^{\circ}$ (T4 scanner) (Kurtz et al., 2013, Krabill et al., 2002, Wang et al., 2016). ATM accomplishes surface elevation measure along the aircraft flight track by reflecting lasers off the ice surface and measuring the time it takes light to return to the aircraft. (Martin et al., 2012) estimated that ATM system for Operation IceBridge (OIB) campaigns have $74 \mathrm{~cm}$ horizontal accuracy, $6.6 \mathrm{~cm}$ vertical accuracy, and $3 \mathrm{~cm}$ vertical precision. 
The ATM L1B data are IceBridge ATM L1B Qfit Elevation and Return Strength data(Studinger, M. 2010, 2010), which were acquired using the T3 scanner in the 2010 Arctic campaign and have a cross-track width of $370 \mathrm{~m}$, a footprint size of $\sim 1 \mathrm{~m}$ and a 3-4 m along-and across track directions interval (Wang et al., 2013, Kwok et al., 2012). It referenced to the ITRF-2005 reference frame and projected onto the WGS-84 ellipsoid (Farrell et al., 2011, Kurtz et al., 2013).

\subsection{Digital Mapping System}

The DMS is an airborne digital camera system that acquires high resolution $(0.1 \mathrm{~m}$ at altitude of $500 \mathrm{~m})$ natural color and panchromatic imagery from low and medium altitude (Dominguez, R.2010, 2017, Wang et al., 2013). Here, we use the Level 1B geolocated and orthorectified images with spatial resolution of $\sim$ $0.1 \mathrm{~m}$, swath length of $\sim 570 \mathrm{~m}$ and swath width of $\sim 380 \mathrm{~m}$. These images are used to assist in the identification of leads and to determine sea surface height reference by combining the ATM minimum elevation over leads.

\section{METHODOLOGY}

In order to obtain the optimal threshold for calculating the local instantaneous sea surface height in the Arctic Beaufort Sea as an alternative to the manual selection method. This paper presents an improved method that use ATM L1B data and DMS high resolution photographic images to derive a more accurate local sea surface height for referencing snow freeboards for Arctic Beaufort Sea. Sea ice flight data on May 21, 2010 over the Beaufort Sea in Arctic are used, and three sections of L1B files (A, B and $\mathrm{C}$ in Figure 1) in the middle of this flight are selected. Some basic information of these sections is shown in Table 1. DMS L1B images are systematically selected at a image center spatial interval of $1 \mathrm{~km}$ to identify leads that combined with open water and thin sea ice, the local sea level reference is equally within a $\pm 0.5 \mathrm{~km}$ section centered at a DMS image (Wang et al., 2013). Manual selection method and six threshold of $2 \%, 1 \%, 0.5 \%, 0.2 \%, 0.1 \%$ and $0.05 \%$ of the lowest ATM L1B data are used to calculating the local instantaneous sea surface height.

\begin{tabular}{cccc}
\hline Sections & A & B & C \\
\hline L1B files & 20100421 & 20100421 & 20100421 \\
L1B shots & -155109 & -154315 & -153124 \\
Length $(\mathrm{km})$ & 35.9 & 35.7 & 36.2 \\
DMS images & 180 & 180 & 180 \\
Selected images & 37 & 36 & 36 \\
Selected images & 24 & 23 & 24 \\
with leads & & &
\end{tabular}

Table 1. Some information about selected three sections of ATM L1B files and the DMS images

Firstly, the local SSH is obtained by manual examination of ATM L1B heights over leads or thin ice identified on images simultaneously acquired from the DMS camera. Ten lowest ATM L1B elevation points that fall into the leads (open water or thin sea ice) are manually selected, and the average value is taken as the SSH reference value (Hr) after excluding the abnormal values by one standard deviation.

Secondly, Six different low elevation thresholds of $2 \%, 1 \%$, $0.5 \%, 0.2 \%, 0.1 \%$ and $0.05 \%$ are used to calculate $\mathrm{SSH}$. In A, $\mathrm{B}$ and $\mathrm{C}$ sections, The most favorable comparison against the sea

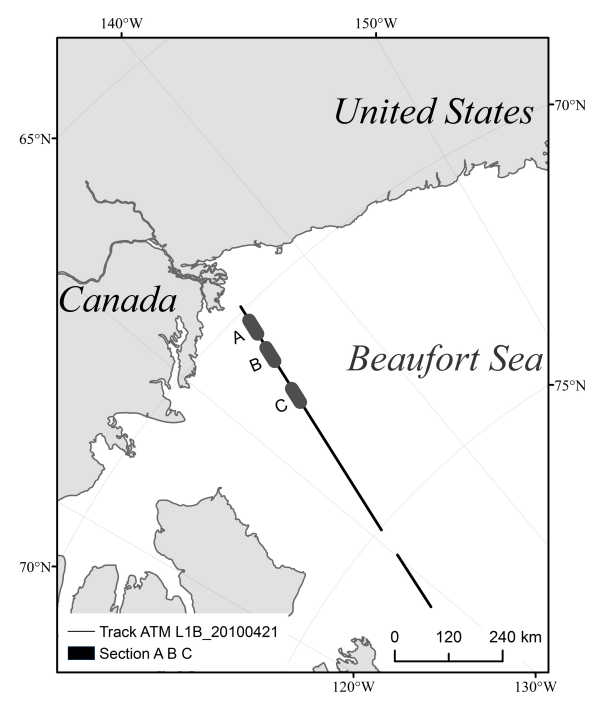

Figure 1. The IceBridge sea ice flight in the Beaufort Sea of Arctic on May 21, 2010 and three selected study sections of A, $\mathrm{B}$ and $\mathrm{C}$

level reference obtained from the manual selection method are chosen as the opital threshold over the same profile; for these selected images without any leads or with too few leads, the SSH is estimated by linear interpolation derived from sea level heights on DMS image areas with leads (Wang et al., 2013). The local instantaneous sea surface height obtained from the optimal threshold method of ATM L1B data is then used as the local sea surface reference, snow freeboard equals ATM L1B elevation on snow surface (or ice) minus it.

\section{RESULTS AND DISCUSSIONS}

\subsection{Results}

According to the above experimental method, the mean difference of sea surface heights derived from threshold method calculations using six thresholds $(2 \%, 1 \%, 0.5 \%, 0.2 \%, 0.1 \%$ and $0.05 \%$ ) and from ATM L1B manual selection on the three sections be summarized in Table 2 .

\begin{tabular}{ccccccc}
\hline \multirow{2}{*}{ Sections } & \multicolumn{6}{c}{ Mean difference (Threshold - Hr) (m) } \\
\cline { 2 - 7 } & $2 \%$ & $1 \%$ & $0.5 \%$ & $0.2 \%$ & $0.1 \%$ & $0.05 \%$ \\
\hline A & 0.169 & 0.129 & 0.087 & 0.034 & -0.002 & -0.036 \\
B & 0.171 & 0.128 & 0.087 & 0.037 & 0.003 & -0.029 \\
C & 0.158 & 0.116 & 0.076 & 0.028 & -0.006 & -0.036 \\
MMD (m) & 0.166 & 0.124 & 0.083 & 0.033 & 0.002 & -0.034 \\
$\begin{array}{c}\text { Mean L1B } \\
\text { points }\end{array}$ & 347 & 173 & 87 & 35 & 17 & 8 \\
\hline
\end{tabular}

Table 2. The mean difference of sea surface heights derived from threshold method and manual selection over selected DMS images with leads

From table 2, the mean of mean difference(MMD) between the lowest ATM L1B data threshold of $2 \%, 1 \%, 0.5 \%, 0.2 \%, 0.1 \%$ and $0.05 \%$ and those derived from manual selection over DMS images with leads, which are $0.166 \mathrm{~m}, 0.124 \mathrm{~m}, 0.083 \mathrm{~m}, 0.018 \mathrm{~m}$, $0.002 \mathrm{~m}$ and $-0.034 \mathrm{~m}$. Among them, when the threshold is reduced from $2 \%$ to $0.05 \%$, the mean of mean difference decrease 
monotonically. The averaged instantaneous sea surface heights of the lowest $2 \%$ of L1B data over DMS images are $0.166 \mathrm{~m}$ of mean average difference higher than those from the L1B manual selection, the mean average differences are $0.034 \mathrm{~m}$ lower than those from the L1B manual selection, the threshold reaches $0.1 \%$ has the smallest difference $(0.002 \mathrm{~m})$ with those from manual selection. Therefore, the lowest elevation threshold of $0.1 \%$ is used as the optimal threshold for calculating the instantaneous sea level in the local area of the Beaufort Sea.

The mean absolute difference (MAD) of sea surface derived from the optimal threshold of $0.1 \%$ method and from L1B manual selection over DMS images with leads, which are $0.01 \mathrm{~m}, 0.02 \mathrm{~m}$ and $0.03 \mathrm{~m}$ and the correlation of SSH between optimal threshold of $0.1 \%$ method and manual selection method are $99.7 \%, 99.5 \%$ and $99.41 \%$ for A, B and C respectively. Figure 4 demonstrate that the SSH calculated by optimal threshold of $0.1 \%$ and the manual selection are generally close.
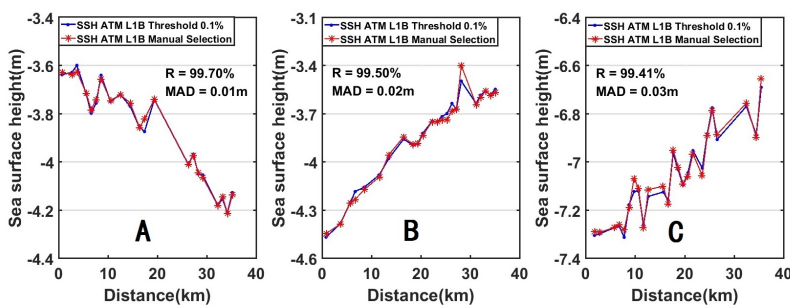

Figure 2. Sea surfacel heights derived from L1B manual selection and the threshold of $0.1 \%$ method over DMS images with leads along the flight direction ( $\mathrm{C}$ to $\mathrm{A})$, respectively for $\mathrm{A}$, $\mathrm{B}$ and $\mathrm{C}$

\subsection{Problems and Improvements}

In the course of our experiments (section C), the method of systematically selecting images at equal intervals of $1 \mathrm{~km}$ between the images are found to have some defects, such as there are no leads or less leads in the selected experimental images, and the nearby images with more leads are discarded. To a certain extent, this will directly affect the accuracy of instantaneous sea surface height calculation in this image region, and indirectly affect the accuracy of interpolation results. For this reason, we propose that experimental images should be selected with more leads.


Figure 3. Under improvements method, Sea surface heights derived from L1B manual selection and the threshold of $0.1 \%$ method over DMS images with leads along the flight direction (C to A), respectively for A, B and C

When we use improved images selection method, the mean absolute difference of the sea surface height between the lowest elevation method of $0.1 \%$ and L1B manual selection is smaller than Figure 3 and Figure 2, the correlation of sea surface height between the optimal threshold method and the manual method is stronger. Therefore, the optimal threshold method can approximate replacement manual method to calculate local instantaneous sea surface height over images with leads.

The determination coefficient (R2) is an index for judging the fitting effect of the model and can be used as a measurement of the degree of fit of the estimated value with the observation value. The closer R2 is to 1 , the better the fit of the estimated value to the observed value. In the three sections of $\mathrm{A}, \mathrm{B}$, and $\mathrm{C}$, as shown in Figure 4, the sea surface height directly calculated by the $0.1 \%$ threshold method over an images with leads has an obvious linear relationship with the distance (away from the beginning per section, along flight direction from $\mathrm{c}$ to a), and its determination coefficient are $94.65 \%, 96.17 \%$ and 95.60 for $\mathrm{A}, \mathrm{B}$ and $\mathrm{C}$ respectively. For these images without leads, the local instantaneous sea surface height estimated using the linear equations between distance and sea surface height calculated over images with leads.
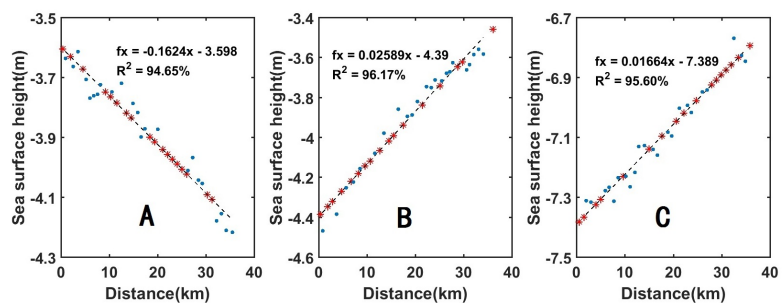

Figure 4. Scatter plots of sea level heights derived from the optimal method over DMS images with leads against the image distance

\subsection{Error and Uncertainty Analysis}

Generally, the precision of local sea surface is affected by many factors. In addition to the systematic errors existing in the ATM system itself, the average height of the sea surface was calculated by the lowest 10 elevations falling in the leads from the average of over 16,000 footprints overlay the image. This is a very heavy workload and is easy subject to human factors. Some melting ponds can be found from DMS images. Although the footprints which fall into the melting pond are low, it does not represent the instantaneous sea surface height. When manually selecting the lowest elevation point, these points need to be removed. Abnormally low elevation measurements may occur since the ATM's green wavelength laser energy can penetrate into open water, and these points also need to be rejected.

\section{CONCLUSIONS}

This paper determined the optimal threshold and developed an improved method used to compute the local instantaneous sea surface height in Beaufort sea. Mean Difference (MD) of SSHs between using $2 \%, 1 \%, 0.5 \%, 0.2 \%, 0.1 \%$ and $0.05 \%$ of the lowest L1B elevation threshold method and those derived from manual selection over leads identified by DMS images are $0.166 \mathrm{~m}$, $0.124 \mathrm{~m}, 0.083 \mathrm{~m}, 0.018 \mathrm{~m}, 0.002 \mathrm{~m}$ and $-0.034 \mathrm{~m}$ respectively. The $\mathrm{SSH}$ from the threshold method of $0.1 \%$ have the smallest difference $(0.002 \mathrm{~m})$ and are used as the local instantaneous sea surface reference in Arctic Beaufort Sea area. After improving image selection method in experiment, The mean absolute difference are reduced by $0.01 \mathrm{~m}$ and $0.02 \mathrm{~m}$ for $\mathrm{B}$ and $\mathrm{C}$ respectively. There is significant effect especially in the experimental section 3. We can use ATM and DMS data to obtain a local instantaneous sea surface height, it can be used as SSH reference of ATM data to calculate the snow freeboard. 


\section{ACKNOWLEDGEMENTS}

This work is supported by the National Key Research and Development Program of China (2017YFA0603104), National Natural Science Foundation of China (41730102, 41531069), Independent Scientific Research Program for Cross-disciplinary of Wuhan University (2042017kf0209). We thank the National Snow and Ice Data Center (NSIDC) for providing experimental data.

\section{REFERENCES}

Connor, L. N., Laxon, S. W., Ridout, A. L., Krabill, W. B. and Mcadoo, D. C., 2009. Comparison of envisat radar and airborne laser altimeter measurements over arctic sea ice. Remote Sensing of Environment 113(3), pp. 563-570.

Dominguez, R.2010, 2017. IceBridge DMS L1B Geolocated and Orthorectified Images, Version 1. [Arctic]. Boulder, Colorado USA. NASA National Snow and Ice Data Center Distributed Active Archive Center. doi: https://doi.org/10.5067/OZ6VNOPMPRJ0.

Farrell, S. L., Markus, T., Connor, L. N. and Miller, J. A., 2011. Laser altimetry sampling strategies over sea ice. Annals of Glaciology volume 52(57), pp. 69-76(8).

Krabill, W. B., Abdalati, W., Frederick, E. B., Manizade, S. S., Martin, C. F., Sonntag, J. G., Swift, R. N., Thomas, R. H. and Yungel, J. G., 2002. Aircraft laser altimetry measurement of elevation changes of the greenland ice sheet: technique and accuracy assessment. Journal of Geodynamics 34(34), pp. 357-376.

Kurtz, N. T., Farrell, S. L., Studinger, M. and Galin, N., 2013. Sea ice thickness, freeboard, and snow depth products from operation icebridge airborne data. Cryosphere 7(4), pp. 1035-1056.

Kurtz, N. T., Markus, T., Cavalieri, D. J., Krabill, W., Sonntag, J. G. and Miller, J., 2008. Comparison of icesat data with airborne laser altimeter measurements over arctic sea ice. IEEE Transactions on Geoscience Remote Sensing 46(7), pp. 1913-1924.

Kwok, R., Cunningham, G. F., Manizade, S. S. and Krabill, W. B., 2012. Arctic sea ice freeboard from icebridge acquisitions in 2009: Estimates and comparisons with icesat. Journal of Geophysical Research Oceans 117(C2), pp. 1-14.

Kwok, R., Zwally, H. J. and Yi, D., 2004. Icesat observations of arctic sea ice: A first look. Geophysical Research Letters 31(16), pp. 171-184.

Martin, C., Krabill, W., Manizade, S., Russell, R., Sonntag, J., Swift, R. and Yungel, J., 2012. Airborne Topographic Mapper Calibration Procedures and Accuracy Assessment, NASA Technical Reports. Vol.20120008479(NASA/TM2012-215891,GSFC.TM.5893.2012),

http://hdl.handle.net/2060/20120008479.

Onana, V., Kurtz, N. T., Farrell, S. L., Koenig, L. S., Studinger, M. and Harbeck, J. P., 2012. A sea-ice lead detection algorithm for use with high-resolution airborne visible imagery. IEEE Transactions on Geoscience and Remote Sensing 51(1), pp. 38 56.

Price, D., Beckers, J., Ricker, R., Kurtz, N., Rack, W., Haas, C., Helm, V., Hendricks, S., Leonard, G. and Langhorne, P. J., 2015. Evaluation of cryosat-2 derived sea-ice freeboard over fast ice in mcmurdo sound, antarctica. Journal of Glaciology 61(226), pp. 285.
Studinger, M. 2010, 2010. Geographic Resources Analysis Support System (GRASS) Software, Version 6.4. Boulder, Colorado USA. NASA National Snow and Ice Data Center Distributed Active Archive Center,https://doi.org/10.5067/DZYNOSKIG6FB.

Wang, X., Guan, F., Liu, J., Xie, H. and Ackley, S., 2016. An improved approach of total freeboard retrieval with icebridge airborne topographic mapper (atm) elevation and digital mapping system (dms) images. Remote Sensing of Environment 184, pp. 582-594.

Wang, X., Xie, H., Ke, Y., Ackley, S. F. and Liu, L., 2013. A method to automatically determine sea level for referencing snow freeboards and computing sea ice thicknesses from nasa icebridge airborne lidar. Remote Sensing of Environment 131(6), pp. 160172.

Yi, D., Zwally, H. J. and Robbins, J. W., 2011. Icesat observations of seasonal and interannual variations of sea-ice freeboard and estimated thickness in the weddell sea, antarctica (2003-2009). Annals of Glaciology 52(57), pp. 43-51.

Zhang, J., Stegall, S. T. and Zhang, X., 2018. Windsea surface temperaturesea ice relationship in the chukchibeaufort seas during autumn. Environmental Research Letters 13(3), pp. 034008.

Zwally, H. J., Yi, D., Kwok, R. and Zhao, Y., 2008. Icesat measurements of sea ice freeboard and estimates of sea ice thickness in the weddell sea. Journal of Geophysical Research Oceans 113(C2), pp. 1-17. 